\title{
Variation of Marshall Properties of Hot Mix Asphalt Concrete with Waste Materials
}

\author{
Rillagoda G.N.Yasanthi ${ }^{1}$, Terrance M.Rengarasu ${ }^{2}$, and W.M.K.R.T.W.Bandara ${ }^{3}$
}

\begin{abstract}
This paper summarizes the findings of research on reusing the waste materials as raw materials in asphalt construction. Saw dust, PET and asphalt waste were tested during the study. The Marshall and volumetric properties resulted confess the suitability of reusing the tested waste materials. As per the study, saw dust is suitable as a partial replacement of filler in asphalt concrete. The recommended content of Saw Dust Ash (SDA) is $2.74 \%$ of the total aggregate weight. Polyethylene Terephthalate (PET) fibres of $3 \mathrm{~cm}$ length and a content of $2 \%$ by total aggregate weight is recommended. Asphalt waste can be successfully reused, without reducing the quality of the mix. However, the replacement rate should be deduced upon the characteristics of the waste sample. By the replacements, the cost can be reduced by about $9.5 \%$ for SDA and about $16.6 \%$ for asphalt waste from the original cost of asphalt production.
\end{abstract}

Keywords-Asphalt Concrete, Filler, Marshall Test, Waste materials

\section{INTRODUCTION}

$\mathrm{W}$ ITH the depletion of natural resources and risen environmental awareness, need for a sustainable flexible pavement design is highly felt. In Sri Lanka, crushed stones (Gneiss), bitumen and stone dust (filler) are the basic raw materials used in asphalt construction. $100 \%$ of the bitumen for the road construction is imported. Further, the production process of stone dust is costly, as well as carbon intensive. Therefore, the cost of asphalt concrete is also high.

The road network system consist of different classes of roads with different traffic loads experienced by the road. Most importantly, the $\mathrm{C}$ class and $\mathrm{D}$ class roads undergo a very low traffic load compared to the other types of national highways. However, virgin raw materials are used in the construction of pavements regardless of the traffic load faced by the pavement.

The estimated municipal solid waste generation in Sri Lanka was $0.89 \mathrm{~kg} / \mathrm{cap} /$ day in 1999 and the prediction for 2025 is 1.0 $\mathrm{kg} / \mathrm{cap} /$ day [1]. Reusing of the solid waste generated in another source will provide a very feasible solution to the solid waste

Rillagoda G.N. Yasanthi ${ }^{1}$ is attached to Faculty of Engineering, University of Ruhuna, Galle, Sri Lanka.

Terrance M. Rengarasu ${ }^{2}$, is a senior lecturer attached to Faculty of Engineering, University of Ruhuna, Galle, Sri Lanka.

W.M.K.R.T.W. Bandara ${ }^{3}$ is a senior lecturer attached to Faculty of Engineering, University of Ruhuna, Galle, Sri Lanka. problem. There are many studies carried out on reusing several waste materials as raw materials in construction industry [2][4]. Reusing fly ash was investigated by many researchers and they ended up with favourable results upon reusing [5]-[7]. It was revealed that Rice Husk Ash (RHA) can be used to replace $50 \%$ of the filler used in an asphalt mix [8]. The waste plastics can also be reused as an additive in stone mastic asphalt [9].

This study aims to introduce waste materials as substitutes for raw materials in asphalt concrete. The reusing will lower the cost of asphalt concrete and better properties can be achieved by the replacement. The asphalt concrete produced with waste materials can be used for local roads and it will be advantageous to a country's budget. Concurrently, the reusing will reduce the landfills as well as open dumping. Therefore, a better appearance of the environment and solutions for problems related with waste disposal can be achieved. The objective of the research is to identify (1) the trends in variation of Marshall Properties, (2) optimum binder content and (3) the optimum filler replacement rate with the waste materials tested.

\section{METHODOLOGY}

The study was carried out according to standard Marshall Procedure. The aggregates and bitumen used were collected from local suppliers to the road construction. In terms of waste materials, the saw dust collected belonged to one type, Albesia (Albizia Julibrissin). The Polyethylene terephthalate (PET) used, were extracted from waste plastic bottles. The asphalt waste tested were scraped road paving materials removed due to failure after design life.

\section{A. Sample Casting}

The samples were cast according to standard method of casting according to Marshall Mix design. The mix proportion for each and every sample was selected according to CIDA specifications [10]. The bitumen percentage was varied from $4 \%$ to $6 \%$ from the total weight of the mix, varying in $0.5 \%$ intervals. The standard number of 50 blows per each side was applied to compact the samples under the required traffic load. To average the properties, several samples were cast from each category. 


\section{Control Sample}

A control sample was cast to compare the results. The control sample includes no waste materials. Three samples each were cast for each bitumen percentage used. The total weight of aggregates used in the mix was $1200 \mathrm{~g}$.

\section{Saw Dust}

The saw dust collected were burnt in an anoxic environment to prevent the effect of saw dust type used. As a result of the burning, pure carbon was left as the residue. Therefore, the effect of the quality of saw dust used is eliminated. Saw Dust Ash (SDA) was introduced in varying weights of $30 \mathrm{~g}$ and $50 \mathrm{~g}$ replacing the respective weight of stone dust with an equal volume. In casting, the SDA was first mixed with the coarse and fine aggregates followed by the addition of filler and bitumen. Fig. 1 captures the SDA used during the experiment.

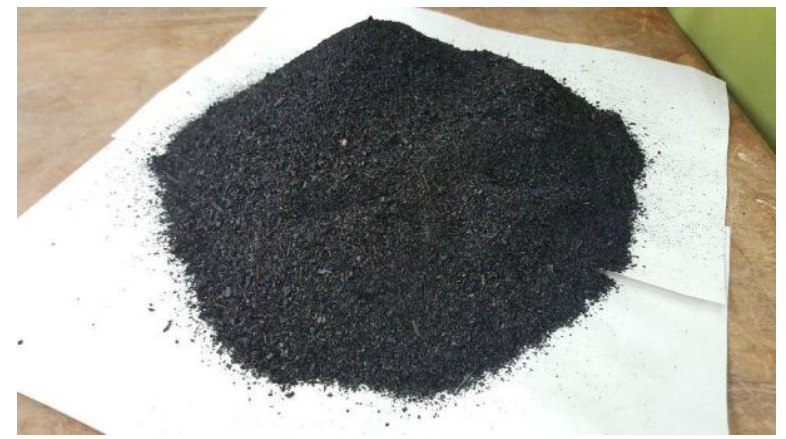

Fig. 1: Saw Dust Ash

\section{PET}

PET was introduced as PET fibres having a diameter of $1 \mathrm{~mm}$. The PET fibres were extracted from waste plastic bottles. The variation of the properties was observed by varying the PET weight $(24 \mathrm{~g}, 36 \mathrm{~g}$, and $48 \mathrm{~g})$ and the length of the fibre $(1 \mathrm{~cm}$ and $3 \mathrm{~cm})$. The PET fibres were introduced to the asphalt mix before mixing the binder and PET was meant to be an additive to the asphalt mix. Fig. 2 captures the PET fibres used during the study.

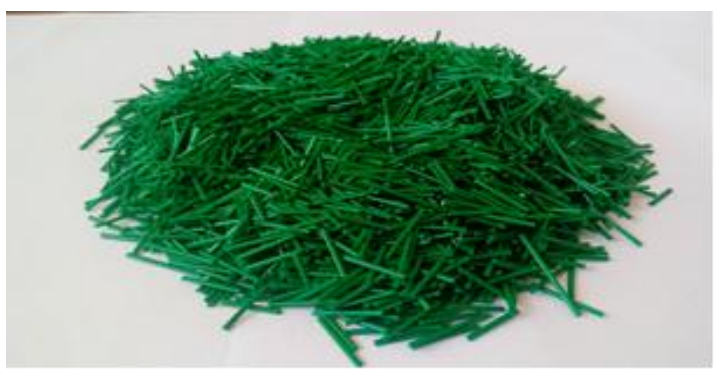

Fig. 2: PET fibres

\section{Asphalt Waste}

The asphalt waste collected (Fig. 3) was first subjected to a bitumen extraction test to find out the inherent bitumen percentage and the combined grading of existing aggregates. The proportions of the aggregates were decided according to the ICTAD specifications and the binder content was reduced according to the existing bitumen content in the waste sample.

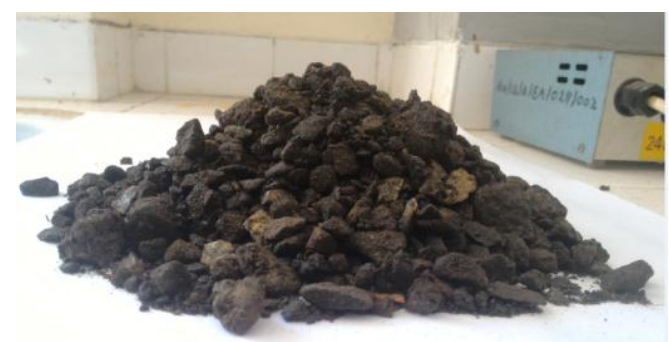

Fig. 3: Asphalt Waste

\section{B. Testing}

The samples were tested for Marshall Stability and Flow value using the Marshall Stability and Flow apparatus. Prior testing the samples, all the samples were kept in a constant temperature bath for 20 minutes at the temperature of 35 degree Celsius. It allows both the surface and the core of the sample to be of same temperature. The temperature of 35 degrees Celsius was selected in order to allow the natural condition faced in the Sri Lankan context. Apart from the Marshall properties, the bulk properties of the samples were determined.

\section{RESULTS AND DISCUSSION}

\section{A. Specific Gravity of Aggregates}

The specific gravities of the aggregates used during the study are presented in Table I.

TABLE I

SPECIFIC GRAVITY OF AGGREGATES

\begin{tabular}{lll}
\hline \hline $\begin{array}{c}\text { Aggregate } \\
\text { Type }\end{array}$ & Specific Gravity(SSD) & $\begin{array}{l}\text { Apparent } \\
\text { Specific Gravity }\end{array}$ \\
\hline $\begin{array}{l}\text { Coarse } \\
\text { Aggregate } \\
\text { Fine }\end{array}$ & 2.648 & 2.27 \\
Aggregate & 2.296 & 2.74 \\
$\begin{array}{l}\text { Stone Dust } \\
\text { Saw Dust }\end{array}$ & 2.506 & 2.64 \\
Ash & - & 0.586 \\
\hline \hline
\end{tabular}

\section{B. Test Results}

The optimum bitumen percentage is averaged considering the optimum bitumen contents corresponding to the maximum stability, maximum bulk specific gravity and the median of designed limits of percent air voids.

\section{Control Sample}

The optimum bitumen percentage resulted is $5.28 \%$ and the average specific gravity of samples is 2.29.

\section{Saw Dust Ash (SDA)}

Average properties of having SDA in asphalt mixes are presented in Table II. 
TABLE II

PROPERTIES OF SAMPLES WITH SDA

\begin{tabular}{lll}
\hline \hline $\begin{array}{c}\text { SDA Weight } \\
(\mathrm{g})\end{array}$ & $\begin{array}{c}\text { Optimum Binder Content } \\
(\%)\end{array}$ & $\begin{array}{c}\text { Average } \\
\text { Specific Gravity }\end{array}$ \\
\hline 30 & 5.5 & 2.00 \\
50 & 5.2 & 1.79 \\
\hline \hline
\end{tabular}

The optimum binder content and the unit weight is reduced with the weight of the SDA used in the asphalt mix. However, the quality of the samples is also reduced with the weight of SDA used in the asphalt mix. The SDA particles are affixed to the aggregate surface during the mixing and casting stages of the samples. When the Ash is introduced to asphalt concrete prior to the addition of binder, the ash is coated with the aggregate surface. Therefore, the cracks present in the aggregate surface are filled and it leads to a better quality of aggregates and a lower binder content. Therefore, a better surface finish can be achieved by using SDA in the asphalt mixes compared to the surface finish achieved in the control samples. Fig. 4 captures two samples from each of control and SDA added groups and it clearly interpret the difference between the two surfaces. Also, when the samples are exposed to hot temperatures, the bleeding compared to the control sample was monitored to be lower.

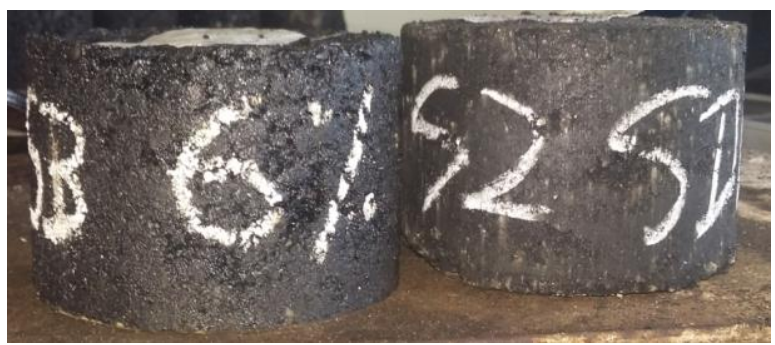

Fig. 4: Control sample (Left), Sample with SDA (Right)

However, the Marshall Stability of the samples having SDA as the filler is low compared to the control sample. When the SDA weight used in the mix is high, the Marshall stability value recorded are lower than the standard value recommended for high traffic loads $(8 \mathrm{kN})$. The variation of Marshall Stability with the binder content for the control sample and the samples cast with SDA as the filler are graphically represented in Fig. 5. The SDA particles are soft and silky. Therefore, the surface texture of the aggregates is soft compared to the aggregates in control sample. Consequently, the strength is reduced in the SDA added samples, compared to the control samples. Due to the absorptive nature of SDA, the bitumen added to the mix is absorbed by the SDA particles. After being saturated, the rest of the bitumen added is acting as the binder to tie up the aggregate skeleton. It leads the thickness of the bitumen film on the surface of aggregates to be reduced. Hence, the total bitumen content has to be increased in order to increase the effective bitumen content which is available to act as the bonding agent.

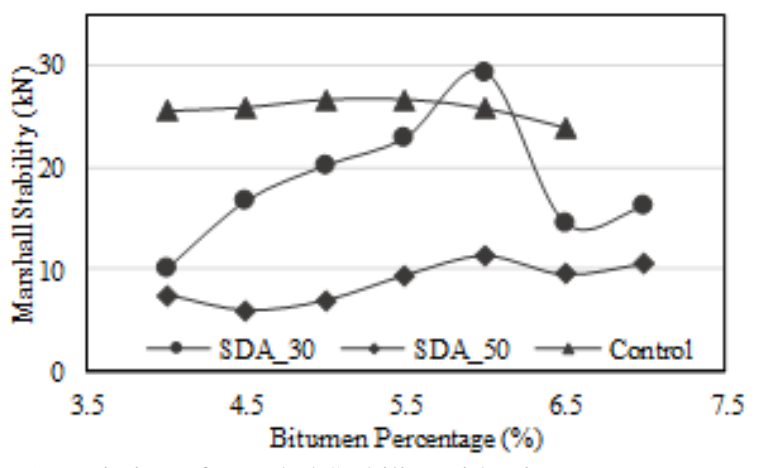

Fig. 5: Variation of Marshal Stability with Bitumen Percentage for Control and SDA samples

Still, the maximum Marshall Stability recorded for samples with $30 \mathrm{~g}$ of SDA is higher than the maximum stability of control sample. That is because, unlike in the control sample, the SDA content itself contain some amount of bitumen absorbed to it. On the other hand, the SDA particles are resting on the aggregate surface, filling the cracks on the coarser aggregates. Therefore, apart from the bitumen film produced on the coarse aggregate surface, an additional film is present in the samples with SDA. It leads to thicken the bitumen film and results in a higher bonding ability compared to control sample.

However, this does not account for higher SDA contents. It is identified to be due to the lack of filler in the mix. When a high amount of SDA is exchanged with stone dust, the replaced weight of filler is quite high $(224 \mathrm{~g})$. It leaves only $496 \mathrm{~g}$ of stone dust and $546 \mathrm{~g}$ of a total weight of filler in the mix. Therefore, the packing of the particles, tightening the skeleton while loading is made difficult. That leads to a reduction of the strength with the increase of SDA content in the mix.

The Marshall Flow is increased with the SDA weight used in the mix (Fig.6). The variation of samples with lesser SDA amount is parallel to the variation in control sample. When the SDA content is increased, the flow is comparatively high. When the SDA amount used is higher, the removed filler amount is also high. Therefore, the inter particle bonds are not strong. It leads the Marshall Flow to be high in samples with a higher SDA content.

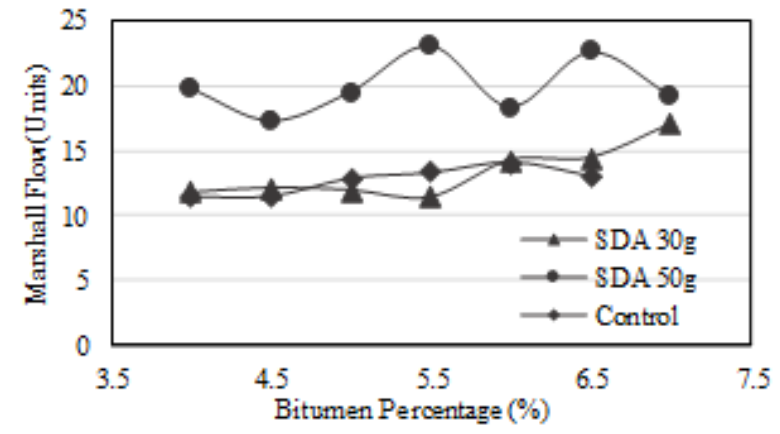

Fig. 6: Variation of Marshal Flow with Bitumen Percentage for Control and SDA samples

The water absorbing patterns of the samples with $30 \mathrm{~g}$ of SDA as aggregates and $6 \%$ bitumen content in the asphalt mix 
were observed and compared with the control sample. The results are graphically interpreted in Fig. 7 and Fig.8.

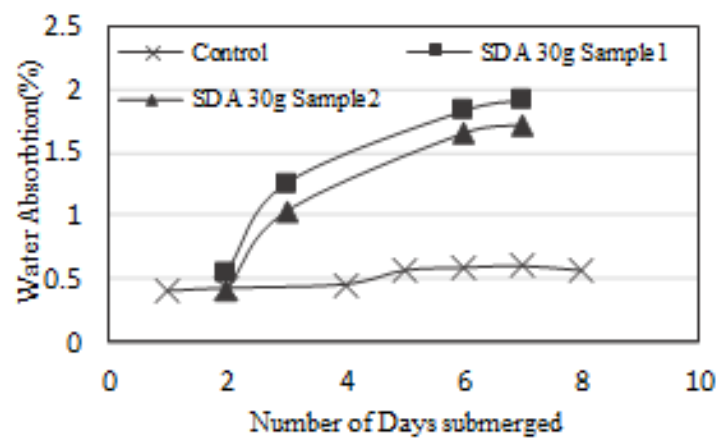

Fig. 7: Water absorption patterns

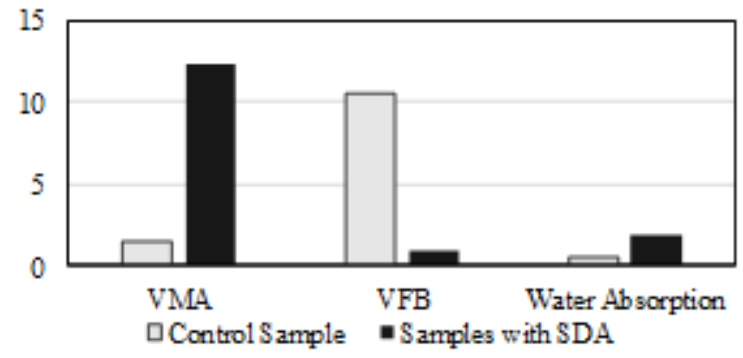

Fig. 8: Physical properties and water absorption of samples

According to Fig. 7, there is a trend of increase in absorbing water in samples cast with SDA, compared to the control sample. In particular, the water absorption in the samples cast with SDA is very high compared to the control sample. As a percentage, the water absorption in the control sample resulted as $0.6 \%$ and for the samples with SDA, the value resulted as about $2 \%$ from the initial weight of the sample in air. This is identified to be due to the inherent water absorbing ability of saw dust ash, which is originally an agricultural element. The saw dust was burnt in an anoxic environment before using in the asphalt mix. Therefore, the residue left was pure carbon for a certain extent. Pure carbon is porous in nature and absorbs water. Therefore, when SDA is used as aggregates in asphalt concrete, it absorbs more water compared to the samples which do not use any SDA.

According to Fig.8, the Voids in Mineral Aggregates (VMA) value is low in the control sample, compared to the samples with SDA. However, the Voids Filled with Bitumen (VFB) value is higher. It indicates that the percentage of voids in the control sample is low, where a higher portion of the voids are even filled with bitumen. Therefore, when the samples of both categories are exposed to water, the control sample having a lower amount of air voids absorbs a lesser amount of water. The samples with SDA have more voids available. Hence, with the introduction of water, the large air pockets absorb and retain water. Eventually, the water absorption is higher in samples cast with SDA.

\section{PET}

PET was tested in two length categories and the properties of each category for PET fibre length of $1 \mathrm{~cm}$ and $3 \mathrm{~cm}$ are presented in Table III and Table IV respectively.
When the PET fibres are introduced to the asphalt mix, part of the PET fibres are melted due to the high mixing temperatures in asphalt production and the other part is left as fibres. Therefore, the PET fibres are used as an additive to the asphalt mix.

TABLE III

PROPERTIES OF SAMPLES WITH 1CM PET FIBRES

\begin{tabular}{|c|c|c|}
\hline $\begin{array}{l}\text { PET content } \\
(\mathrm{g})\end{array}$ & $\begin{array}{c}\text { Optimum Binder Content } \\
(\%)\end{array}$ & $\begin{array}{c}\text { Average } \\
\text { Specific Gravity } \\
\end{array}$ \\
\hline 24 & 4.87 & 2.19 \\
\hline 36 & 4.7 & 2.17 \\
\hline 48 & 5.0 & 2.17 \\
\hline
\end{tabular}

TABLE IV

Properties OF SAMPLES With 3CM Pet Fibres

\begin{tabular}{lll}
\hline \hline $\begin{array}{c}\text { PET content } \\
(\mathrm{g})\end{array}$ & \multicolumn{1}{c}{$\begin{array}{c}\text { Optimum Binder Content } \\
(\%)\end{array}$} & $\begin{array}{c}\text { Average } \\
\text { Specific Gravity }\end{array}$ \\
\hline 24 & 5.03 & 2.23 \\
48 & 4.67 & 2.11 \\
\hline \hline
\end{tabular}

In case of PET, the variation of the Marshall Stability and Marshall Flow did not follow a definite trend for both length categories. Therefore, the Marshall Quotient was used to recommend the optimal PET content. The variation of Marshall Stability, Flow and Marshall Quotient are graphically represented in Fig. 9, 10 and 11 respectively.

The melted part of the PET fibres contributes to the cohesion while the rest act as a reinforcement skeleton inside the sample. The melted portion of the PET is mixed with bitumen and the aggregates are bond further due to the increase in cohesion. Therefore, when PET is introduced to the mix, an additional load is carried out apart from the load taken by the aggregates used in the asphalt mix. As a result, the Marshall stability is increased.

The flow values also have the same problem as the stability. Some values are out of the standard flow value to be used in road construction (8 to 18 units). The reason for such an occurrence is identified as the melted PET fibre causes more displacement due its sticky nature. Rather than increasing the inter particle bonds between the aggregates, the melt PET fibres make the bitumen to shrink more leading to higher deformations. Apart from that, the solid PET fibres remaining in the mix cause the aggregates slip on each other due to the soft, round surface of the fibres. Therefore, when the load is applied, the sample is highly deformed and results in higher flow values. The flow values keep increasing with the PET content. All the flow values except one, are higher than the control samples' flow values. When the PET content is increased, the melted amount of PET is reduced, leading a more flow value.

The Marshall Quotient values lie below the respective values, except for samples with $2 \%$ PET fibres of $3 \mathrm{~cm}$ length. However, the minimum standard value for Marshall Quotient is 0.5 even for roads with high traffic. Therefore, only the sample category with $4 \%$ bitumen on $3 \mathrm{~cm}$ length is 
disqualified.

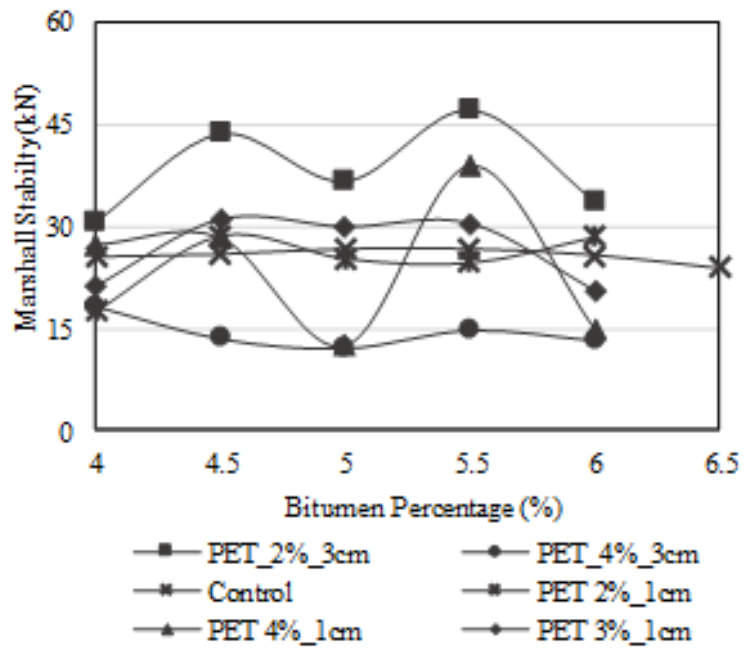

Fig. 9: Variation of Marshall Stability for samples with PET

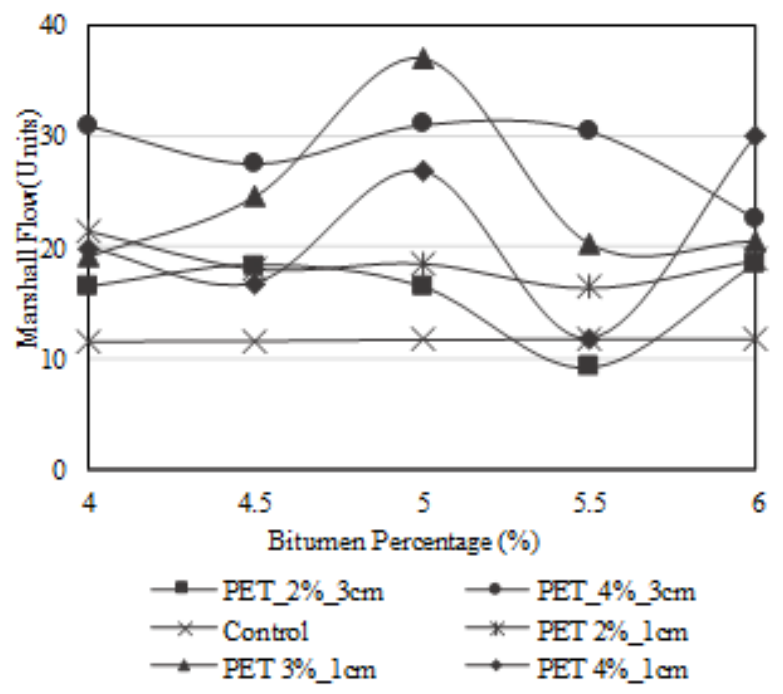

Fig. 10: Variation of Marshall Flow for samples with PET

\section{Asphalt Waste}

The asphalt waste sample collected was subjected to a bitumen extraction test. According to the bitumen extraction test results, the inherent bitumen percentage of the spoil

sample was $1.77 \%$ from the total weight. The combined grading of the existing aggregate in the asphalt mix was observed by a sieve analysis test. The results of the sieve analysis test are presented in Fig. 12.

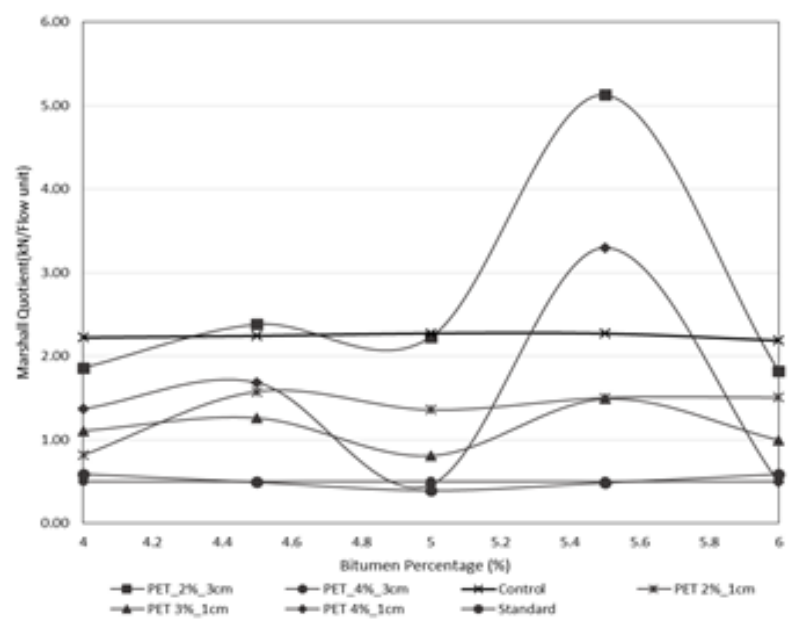

Fig.11: Variation of Marshall Quotient of PET added samples

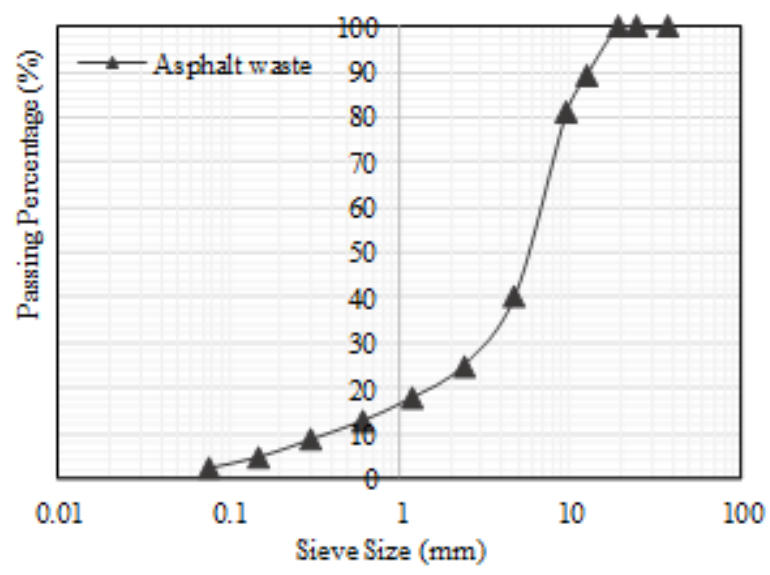

Fig. 12: Grading Curve of Aggregates in Asphalt Waste Sample

The resulted reduction of bitumen by the replacement of the raw materials with asphalt waste was $4.25 \mathrm{~g}$ from all samples. The resulted mix proportion of the aggregates in the asphalt mix was $25 \%, 5 \%, 50 \%$ and $20 \%$ from coarse aggregate, fine aggregate, filler and the spoil waste sample respectively.

The variation of the Marshall Stability when the spoil material is used to replace part of the raw materials in the asphalt mix, is graphically represented in Fig.13. The stability values are increased compared to the control sample, except when the bitumen percentage is 5\%. The increase in the stability is due to the increased thickness of bitumen film on the aggregates. The sample already has a thin bitumen film. Therefore, the additional bitumen added leads to strengthen the sample. The bitumen added additionally to the asphalt mix combine with the existing bitumen particles in the aggregate surfaces and it leads the bond to be made stronger. The inherent bitumen in the waste sample's aggregates have already filled the cracks in the coarser aggregates to some extent. Therefore, the bitumen added are totally reserved to bond the aggregates.

The variation of the Marshall Flow values is graphically represented in Fig.14. The flow values vary parallel to the variation of flow of the control sample. However, the flow values resulted are less compared to the control sample. This 
reduction is resulted due to the increased inter particle bonds between aggregates. The aggregates in the sample are used previously. Therefore, the packing of the aggregates is well defined. Therefore, when the load is applied, it rearranges quickly and reduces the deformation. Ultimately, the Marshall Flow values of the samples when the asphalt waste is used are reduced compared to the control sample.

The properties of the samples having Asphalt waste as a partial replacement of the raw materials are presented in Table V.

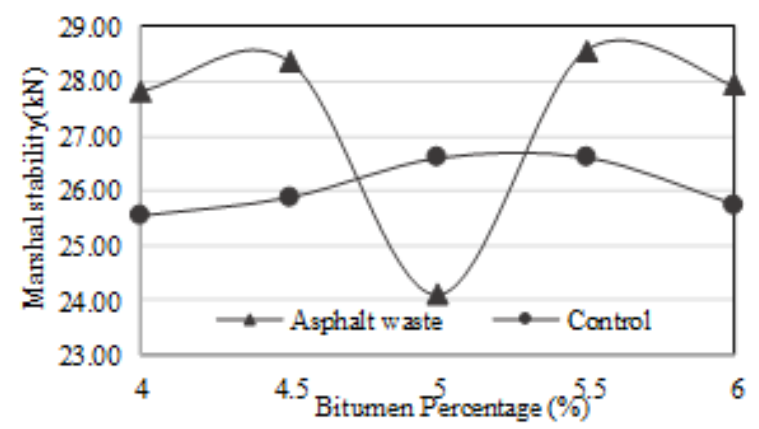

Fig. 13: Variation of Marshall Stability with Asphalt Waste

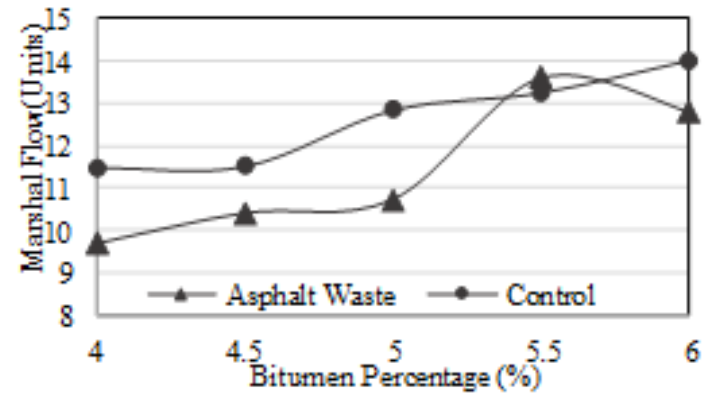

Fig. 14: Variation of Marshall Flow with Asphalt Waste

TABLE V

PRoperties OF SAMPLEs With ASPhalt WASTE

\begin{tabular}{lcc}
\hline \hline $\begin{array}{l}\text { Waste } \\
\text { Material }\end{array}$ & $\begin{array}{c}\text { Optimum Binder Content } \\
(\%)\end{array}$ & $\begin{array}{c}\text { Average } \\
\text { Specific Gravity }\end{array}$ \\
\hline $\begin{array}{l}\text { Asphalt } \\
\text { Waste }\end{array}$ & 5.13 & 2.32 \\
\hline \hline
\end{tabular}

The variation of optimum binder content for all waste material categories tested is graphically represented in Fig. 15.

The Optimum Binder Content is low in all samples with waste materials compared to samples with waste materials with the exception for samples having $30 \mathrm{~g}$ of SDA. The lowest optimum binder content resulted when the samples were added $1 \mathrm{~cm}$ long PET fibres with a content of $3 \%$ weight. The highest resulted for samples with $30 \mathrm{~g}$ of SDA.

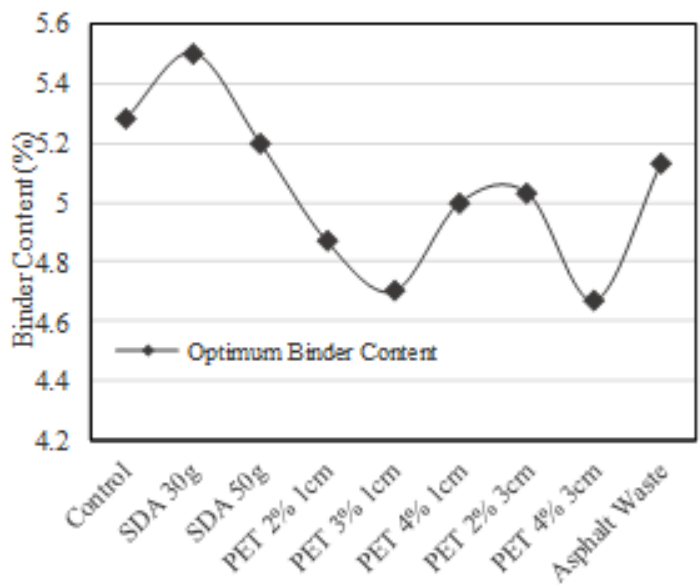

Fig. 15: Variation of Optimum Binder Content

\section{CONCLUSION}

The Marshall Stability decrease with the increase in SDA content used The Marshall Flow increase with the SDA amount. The Marshall Stability and Flow do not follow a definite trend in PET added samples. However, the Marshall Quotient is decreased with the PET amount used in the samples, where the variation relative to the length does not follow a definite trend. The samples reusing asphalt waste resulted higher Marshall Stability values except for one bitumen percentage tested. However, the Marshal Flow variation is in line with the variation of control sample with little discrepancies.

The optimum binder contents for the samples with tested waste materials, resulted lower values compared to the control sample. However, the optimum binder content was high when the SDA amount added was $30 \mathrm{~g}$. With the results, a saw dust ash content of about $3 \%$ from the total aggregate weight of the mix including the saw dust weight can be recommended to be used in Hot Mix Asphalt pavements with low traffic. However, the effects of daily water absorption should be monitored further. The rough cost reduction due to replacement of SDA with the filler is about $9.5 \%$ of the original cost. A PET, weight of $2 \%$ of the total aggregate weight with $3 \mathrm{~cm}$ long fibres can be recommended for real time application for roads with low traffic. Asphalt waste can be reused as raw materials in asphalt concrete production. Yet, the characteristics of the spoil sample should be monitored before reusing the asphalt concrete waste. The cost reduction resulted by reusing, for the waste sample used during the study is about $16.6 \%$.from the original cost of construction.

Although an environmental advantage is realized through the usage of saw dust in asphalt concrete, there is a possibility of the captured carbon being escaped back to the air [11]. This phenomenon will take effect after a certain period of time, when the carbon in SDA reacts with the oxygen in atmosphere and released as Carbon Dioxide. Therefore, the need for further research is pronounced and highly recommended on the topic of carbon escape. Also, the long term effects of the daily introduction of additional water should be further researched. 
In terms of PET, a part of the PET added was melted during the addition of bitumen. Therefore, the variation in the trend of the properties was difficult to identify. Hence, the addition of PET has to be varied and the performance should be monitored. Therefore, further research is recommended to fill out the research gap.

\section{REFERENCES}

[1] C.K. Vidanaarachchi, S.T. Yuen., and S. Pilapitiya, (2006). "Municipal solid waste management in the southern province of sri lanka: Problems, issues and challenges." Waste Management, 26(8), 920-930. http://dx.doi.org/10.1016/j.wasman.2005.09.013

[2] S. Paranavithana and A. Mohajerani, (2006). "Effects of recycled concrete aggregates on properties of asphalt concrete." Resources, Conservation and Recycling, 48(1), 1-12. http://dx.doi.org/10.1016/j.resconrec.2005.12.009

[3] Y. Huang, R. N. Bird and O. Heidrich, (2007). "A review of the use of recycled solid waste materials in asphalt pavements." Resources, Conservation and Recycling, 52(1), 58-73. http://dx.doi.org/10.1016/j.resconrec.2007.02.002

[4] C. Hendriks, and H. Pietersen, (2000). "Sustainable raw materialsconstruction and demolition waste (165-srm)." State-of-the-Art Report of RILEM Technical Committee.

[5] W. Warden, S. Hudson and H. Howell, (1959). "Evaluation of mineral fillers in terms of practical pavement performance." Proceedings of the Association of Asphalt Paving Technologists, Vol. 28, 316-352.

[6] N. Ali, J. Chan, S. Simms, R. Bushman, and A. Bergan, (1996). "Mechanistic evaluation of fly ash asphalt concrete mixtures." Journal of Materials in Civil Engineering, 8(1), 19-25. http://dx.doi.org/10.1061/(ASCE)0899-1561(1996)8:1(19)

[7] S. Tapkin, (2008). "Mechanical evaluation of asphalt-aggregate mixtures prepared with fly ash as a filler replacement." Canadian Journal of Civil Engineering, 35(1), 27-40. http://dx.doi.org/10.1139/L07-082

[8] S. Sargin, M. Saltan, N. Morova, S. Serin and S. Terzi, (2013). "Evaluation of rice husk ash as filler in hot mix asphalt concrete." Construction and Building Materials, 48, 390-397. http://dx.doi.org/10.1016/j.conbuildmat.2013.06.029

[9] E. Ahmadinia, M. Zargar, M. R. Karim, M. Abdelaziz and P. Shafigh, (2011). "Using waste plastic bottles as additive for stone mastic asphalt." Materials \& Design, 32(10), 4844-4849. http://dx.doi.org/10.1016/j.matdes.2011.06.016

[10] CIDA (2009), Standard specifications for construction and maintenance of roads and bridges (SCA/5). Institute of Construction Training And Development.

[11] J. Blackford, N. Jones, R. Proctor, J. Holt, S. Widdicombe, D. Lowe, and A. Rees, 2009. An initial assessment of the potential environmental impact of $\mathrm{CO} 2$ escape from marine carbon capture and storage systems. Proceedings of the Institution of Mechanical Engineers, Part A: Journal of Power and Energy, 223(3), pp.269-280.

http://dx.doi.org/10.1243/09576509JPE623 